\title{
Pneumothorax in AIDS: case reviews and proposed clinical management
}

\author{
D Asboe, M Fisher, M R Nelson, D K Kaplan, K Al-Kattan, B G Gazzard
}

\begin{abstract}
Background: Pneumothorax is a not uncommon complication of advanced HIV infection, and may prove difficult to manage in view of its recalcitrant and recurrent nature. In this group where immunosuppression and reduced life expectancy are a feature, standard protocols are often abandoned in favour of a more conservative approach. This is often unsuccessful.

Methods: Patients attending the Department of Genitourinary Medicine, Chelsea and Westminster Hospital who sustained pneumothorax between 1988 and 1992 were identified retrospectively and their notes reviewed.

Results: Fifteen patients were identified of whom three had post-procedural pneumothoraces. In the remaining 12 patients, 10 had previously had Pneumocystic carinii pneumonia (PCP), whilst all 12 had some evidence to suggest current PCP (seven proven, five presumptive). In those six patients with a single, unilateral pneumothorax, four were managed successfully with intercostal drainage alone (one patient died early, one required pleurectomy). In those with recurrent pneumothoraces or pneumothoraces that did not respond to prolonged intercostal drainage, failure of medical treatment was judged to have occurred and surgery was performed. Overall, conservative management failed in $7 / 11$ patients. Conversely surgery resulted in resolution in $7 / 7$ with recurrence seen in one individual. Median survival was similar in the two groups.

Conclusions: Pneumothorax in patients with AIDS is associated with a high rate of intercurrent PCP; a low threshold for treating this infection presumptively is indicated. Intercostal drainage was successful in patients with a single, unilateral pneumothorax. However, in patients with recurrent or bilateral pneumothorax extended periods on intercostal drainage were uniformly unsuccessful. Early surgical referral should be considered in this group.

(Genitourin Med 1996;72:258-260)
\end{abstract}

Keywords: pneumothorax; HIV infection; PCP

\section{Introduction}

Pneumothorax is a well recognised complication in AIDS, primarily in patients with Pneumocystis carinii pneumonia (PCP).$^{1-8}$ Other reported associations include the use of nebulised pentamidine. ${ }^{45}$ Because of the recalcitrant nature of pneumothorax in a high proportion of patients, and the consequent failure of conservative measures, decisions frequently need to be made about whether to persist with medical therapies or to intervene surgically. Although surgical intervention is known to achieve success in these circumstances ${ }^{9}$ opinion still varies as to how appropriate such procedures may be. ${ }^{10}$ In this report we review our experience of pneumothorax in 15 patients with AIDS and propose a clinical approach to intervention.

\section{Patients and methods}

Within our unit all patients diagnosed as being HIV1 antibody positive have records of their personal history and subsequent HIV care entered upon the departmental computer. From these records for the period between 1988-1992 we identified 15 patients who developed one or more pneumothoraces during the course of their illness. To our knowledge casefinding was complete. On review of the case notes we extracted information regarding demographic characteristics, CD4 count, PCP prophylaxis, and the history, investigation and outcome of each event.

On the diagnosis of pneumothorax, our standard practice initially was to assess the patient to ascertain whether observation or aspiration would be feasible for that individual. If intercostal drainage was required, a chest drain was inserted with an underwater seal and suction of $5-10 \mathrm{~mm}$ water applied. When air leakage ceased the drain was removed. In those cases with persistent leakage, chemical pleurodesis was consideredeither with tetracycline or Corynebacterium parvum.

Failure of medical treatment was the indication for surgical intervention. Posterolateral thoracotomy or median sternotomy was performed to deal with unilateral or bilateral pneumothorax respectively. Complete pleurectomy was the standard procedure; additional methods being used selectively to deal with large air leaks.

\section{Results}

Over the period of study there were 15 patients who experienced pneumothorax. None of these cases were precipitated by mechanical ventilation. Of the 15 , three were iatrogenic-following pleural aspiration $(n=1)$ and transbronchial biopsy $(n=2)$. All three responded within seven days to conventional medical therapy -one without intervention; the other two requiring intercostal 
Intervention and outcome of individuals with non-iatrogenic pneumothorax

\begin{tabular}{|c|c|c|c|c|c|c|c|c|c|c|c|}
\hline $\begin{array}{l}\text { Pneumothorax } \\
\text { type }\end{array}$ & $\begin{array}{l}\text { Patient } \\
\text { number }\end{array}$ & $\begin{array}{l}\text { Pneumo- } \\
\text { thorax } \\
\text { number }\end{array}$ & $\begin{array}{l}\text { Inter- } \\
\text { costal } \\
\text { drainage } \\
\text { (ID) }\end{array}$ & $\begin{array}{l}\text { Pleuro } \\
\text { desis }\end{array}$ & $\begin{array}{l}\text { Max. no } \\
\text { days ID }\end{array}$ & $\begin{array}{l}\text { Out- } \\
\text { come }\end{array}$ & $\begin{array}{l}\text { Operative } \\
\text { details }\end{array}$ & $\begin{array}{l}\text { Surgical } \\
\text { outcome }\end{array}$ & $\begin{array}{l}\text { Length of } \\
\text { post-op } \\
\text { hospitalisation } \\
\text { (days) }\end{array}$ & $\begin{array}{l}\text { Total } \\
\text { length of } \\
\text { hospitalisation } \\
\text { (days) }\end{array}$ & $\begin{array}{l}\text { Survivalt } \\
\text { (days) }\end{array}$ \\
\hline b) Recurrent & $\begin{array}{l}1 \\
2 \\
3 \\
4 \\
5 \\
6 \\
7\end{array}$ & $\begin{array}{l}1 \\
1 \\
1 \\
1 \\
1 \\
1 \\
2\end{array}$ & $\begin{array}{l}\mathrm{Y} \\
\mathrm{Y} \\
\mathrm{Y} \\
\mathrm{Y} \\
\mathrm{Y} \\
\mathrm{Y} \\
\mathrm{Y}\end{array}$ & $\begin{array}{l}\overline{-} \\
\overline{-} \\
\bar{C} \\
\mathrm{~T}\end{array}$ & $\begin{array}{r}3 \\
5 \\
5 \\
3 \\
25 \\
25 \\
15\end{array}$ & $\begin{array}{l}\text { S } \\
\text { S } \\
\text { S } \\
D \\
\text { S } \\
\text { F } \\
\text { F }\end{array}$ & $\begin{array}{l}- \\
\overline{-} \\
\overline{-} \\
\overline{\text { Pleurectomy }} \\
\text { Pleurectomy }\end{array}$ & $\begin{array}{l}= \\
\overline{-} \\
\bar{s} \\
\mathrm{~s}\end{array}$ & $\begin{array}{l}= \\
z \\
= \\
5 \\
5\end{array}$ & $\begin{array}{r}3 \\
7 \\
7 \\
3 \\
32 \\
30 \\
20\end{array}$ & $\begin{array}{l}304 \\
420 \\
247(\mathrm{~A}) \\
\quad 0 \\
(\mathrm{P}) \\
583 \\
676(\mathrm{~A})\end{array}$ \\
\hline $\begin{array}{l}\text { Bilateral } \\
\text { a) Sequential } \\
\text { b) Synchronous }\end{array}$ & $\begin{array}{r}8(\mathbf{R}) \\
(\mathrm{L}) \\
9(\mathrm{R}) \\
(\mathrm{L}) \\
10(\mathrm{R}) \\
(\mathrm{L}) \\
11(\mathrm{R}) \\
(\mathrm{L}) \\
12(\mathrm{R}) \\
(\mathrm{L})\end{array}$ & $\begin{array}{l}1 \\
2 \\
1 \\
1 \\
1 \\
1 \\
1 \\
1 \\
1 \\
1 \\
1\end{array}$ & $\begin{array}{l}\mathrm{Y} \\
\mathrm{Y} \\
\mathrm{Y} \\
\mathrm{Y} \\
\mathrm{Y} \\
\mathrm{Y} \\
\mathrm{Y} \\
\mathrm{Y} \\
\mathrm{Y} \\
\mathrm{Y}\end{array}$ & $\begin{array}{l}\frac{C}{T} \\
\frac{T}{C} \\
\frac{T}{T} \\
\frac{-}{-}\end{array}$ & $\begin{array}{l}16 \\
13 \\
22 \\
12 \\
10 \\
19 \\
13 \\
37 \\
24 \\
22\end{array}$ & $\begin{array}{l}F \\
F \\
F \\
S \\
F \\
F \\
S \\
F \\
F \\
F\end{array}$ & $\begin{array}{l}\text { Pleurectomy } \\
\text { Pleurectomy } \\
\text { Pleurectomy } \\
\overline{\text { Bilateral }} \\
\text { pleurectomy } \\
\overline{\text { Pleurectomy }} \\
\begin{array}{l}\text { Bilateral } \\
\text { pleurectomy }\end{array}\end{array}$ & $\begin{array}{l}S \\
S \\
S \\
S \\
S \\
S \\
F \\
F\end{array}$ & $\begin{array}{r}15 \\
5 \\
30 \\
28 \\
- \\
10 \\
9\end{array}$ & $\begin{array}{l}31 \\
18 \\
52 \\
47\end{array}$ & $\begin{array}{l}\frac{123}{31} \\
\frac{-}{310(\mathrm{~A})} \\
- \\
- \\
96 \\
356\end{array}$ \\
\hline
\end{tabular}

$\star$ Patients 6,8 and 12 had additional resection of bullae and patient 10 had pleural stapling.

tSurvival figures are taken from the final removal of intercostal drains following definitive treatment, be it medical or surgical.

Key: A, alive at time of analysis; D, death (respiratory failure); S, success; F, failure; $\mathrm{Y}$, tube throacostomy performed; C, Corynebacterium; T, tetracycline; P, lost to follow-up.

drainage, one with additional chemical pleurodesis. In the remaining 12 patients the pneumothoraces were apparently spontaneous. The clinical course of these patients is summarised in the table.

The median age was 31 years (range 20-43) and all were gay men, reflecting the predominant client group seen in our unit. All patients were markedly immunosuppressed; the median CD4 count being $22 / \mathrm{mm}^{3}$ (range 3-85). Of these 12 patients, four were currently using nebulised pentamidine, two co-trimoxazole, two dapsone, one fansidar and one intravenous pentamidine as PCP prophylaxis. Two individuals were not taking any form of prophylaxis.

Ten patients had one or more prior episodes of PCP (mean of 1.5 episodes for each patient). Seven patients had proven current PCP on the basis of induced sputum or broncho-alveolar lavage analysis. The remaining five patients had presumptive PCP on the basis of clinical (non-productive cough, exertional dyspnoea) and/or radiological findings (bilateral interstitial infiltrates on chest $x$ ray). Bronchoscopy was not performed in this group because of marked hypoxia.

In all the non-iatrogenic cases the size of the pneumothorax or the degree of respiratory compromise was such that neither observation nor aspiration alone were considered. Intercostal drainage with suction was successful in four out of the six patients with a single, unilateral pneumothorax. One patient died at three days from respiratory failure, whilst one patient required pleurectomy after 25 days drainage and suction without resolution. Of those cases in which thoracostomy was unsuccessful, chemical pleurodesis was attempted in six, failing on each occasion. All six patients with bilateral or recurrent pneumothorax eventually proceeded to surgery after prolonged periods of intercostal drainage. Only two of the 11 involved lungs in this group were able to be managed successfully by nonoperative methods.

Surgery resulted in successful resolution of pneumothorax in all seven patients (10 pneumothoraces). In patient 12, bilateral recurrence occurred following discharge. This was managed successfully by the insertion of Heimlich valves.

In the group of six patients who had pneumothorax successfully dealt with medically, median time spent on intercostal drainage was 8.5 days (although two of this group did eventually require surgery). This contrasts with the group who proceeded to surgery, failing medical therapy after a median 22 days intercostal drainage. Six out of the seven patients operated on, were alive three months following surgery with median survival of 310 days.

\section{Discussion}

This study confirms the significant association of pneumothorax with PCP in AIDS. Previous reports suggest an incidence of pneumothorax in $6-9 \%$ of patients with PCP. ${ }^{78}$ As PCP remains one of the most common opportunistic infections seen in such individuals this represents a substantial contribution to morbidity. In addition to a past history seen in the majority, all patients had evidence to suggest intercurrent PCP. Although the numbers are too small to draw firm conclusions it is possible that pneumothorax is associated with active PCP rather than existing lung damage from previous episodes.

One third of the patients were using nebulised pentamidine during the period immediately preceding the pneumothorax. In our unit, over the time period studied, $28 \%$ of patients considered at risk of developing PCP used nebulised pentamidine as their prophylactic agent. Although this does not support the assertion of other authors that the use of nebulised pentamidine is associated with a higher risk of pneumothorax, it is our policy not to recommend this form of prophylaxis after pneumothorax has occurred.

The time spent on intercostal drainage was short for those patients in whom this procedure was sufficient for resolution. Whilst for 
those who proceeded to surgery it is not possible to know whether prolonged intercostal drainage would have resulted in resolution, we speculate that these were true medical failures. With a median 22 days on drainage before opting for surgery, we believe a reasonable medical trial was given. The success rate of only $38 \%$ for medical intervention is comparable with the $26 \%$ achieved after a mean $18 \cdot 1$ days hospitalisation in the series reported by Wait et al. ${ }^{11}$

Prolonged conservative management is not a risk free approach. As well as the potential for acquisition of nosocomial infection and the consequences of extended periods of restricted mobility, there are obvious implications for quality of life. If the patients likely to fail medical treatment could be identified and referred early for surgery, the prolonged time spent on drainage could be avoided. Our findings suggest that pneumothorax recurrence or bilaterality could form one part of such identification.

Although the rate of surgical intervention reported here was higher than in some previous studies, ${ }^{48}$ the success rate was also high. Complete surgical resolution was achieved in all seven patients though in one there was recurrence bilaterally. This represents an $80 \%$ success rate for the 10 lungs involved, compared with the $93 \%$ by Crawford et al. ${ }^{9}$ None of these patients had problems with significant wound infections, and the 1 early death (at 31 days) was not directly attributable to surgery.

It has previously been suggested that the survival of patients with recalcitrant pneumothorax is short; $^{6}$ however, we found a median survival of almost one year. Though we would disagree with the assertion that surgery is contraindicated per se because of immunosuppression, the availability of less invasive techniques such as video assisted talc poudrage ${ }^{11}$ may allow optimisation of outcome without the need for open surgery.

Pneumothorax is a significant complication in AIDS patients. Following the association with intercurrent Pneumocystis carinii infection we would suggest that in all immunosup- pressed HIV positive patients with spontaneous pneumothorax there be a high diagnostic suspicion of active PCP. Those patients with an iatrogenic or a single, unilateral pneumothorax would be expected to respond to conventional medical therapy, and therefore should be managed in much the same way as a non HIV infected patient. It is important that the initial medical management is optimised, by the use of a large bore intercostal tube (or tubes) and suction. We have identified patients with bilateral or recurrent pneumothorax as a group in whom early referral for thoracic surgery may be beneficial. In this patient group we confirm surgery is both successful in the short term and considering the circumstances associated with reasonable survival, though it would be worthwhile confirming this with prospective evaluation of a management protocol. We do not believe that HIV positivity and immunosuppression in themselves should be considered contraindications to surgery.

1 Fleischer AG, McElvaney G, Lawson L, Gerein AN, Gran D, Tyers GF. Surgical management of spontaneous pneumothorax in patients with acquired immunopneumothorax in patients with acquired immunct

2 Byrnes TA, Brevig JK, Yeoh CB. Pneumothorax in patients with acquired immunodeficiency syndrome. $f$ Thorac Wardiovasc Surg 1989;98:546-50.

3 Feuerstein IM, Archer A, Pluda JM, et al. Thin-walled cavities, cysts and pneumothorax in Pneumocystis carini pneumonia: further observations with histopathologic correlation. Radiology 1990;174:697-702.

4 Newsome GS, Ward DJ, Pierce PF. Spontaneous pneumothorax in patients with acquired immunodeficiency syndrome treated with prophylactic aerosolised pentamidine. Arch Int Med 1990;150:2167-8.

5 Sepkowitz KA, Telzak EE, Gold JW et al. Pneumothorax in AIDS. Ann Intern Med 1991;114:455-9.

6 Gerein AN, Brumwell ML, Lawson LM, Chan NH Montaner JS. Surgical management of pneumothorax in patients with acquired immunodeficiency syndrome. patients with acquired im
Arch Surg 1991;126:1272-7.

7 McClellan MD, Miller SB, Parsons PE, Cohn DL Pneumothorax with Pneumocystis carinii pneumonia in AIDS. Chest 1991;100:1224-8.

8 Coker RJ, Moss F, Peters B, et al. Pneumothorax in patients with AIDS. Resp Med 1993;87:43-7.

9 Crawford BK, Galloway AC, Boyd AD, Spencer FC. Treatment of AIDS-related bronchopleural fistula by pleurectomy. Ann Thoracic Surgery 1992;54:212-5.

10 Mitchell DM, Miller RF. New developments in the pulmonary diseases affecting HIV infected individuals. Thorax 1995;50:294-302.

11 Wait MA, Dal Nogare AR. Treatment of AIDS-related spontaneous pneumothorax. Chest 1994;106:693-6. 